\title{
Own health, spousal health and transitions in loneliness among middle-aged and older adults in China
}

\author{
Ye Luo \\ Department of Sociology, Anthropology and Criminal Justice, Clemson University, Clemson, South \\ Carolina, USA \\ Email: yel@clemson.edu
}

(Accepted 2 August 2021)

\begin{abstract}
This study examines the effects of own and spousal health on transitions in loneliness over time among married middle-aged and older adults in China, and explores the possible gender differences in these effects using data from the three waves of the China Health and Retirement Longitudinal Study (2011-2015). The sample includes 6,422 men and 6,391 women who were married and aged 45 and older at the baseline survey. Middleaged and older adults with poorer physical and emotional health statuses are more likely to transition into and less likely to transition out of loneliness in a two-year period. Spouse's emotional health also affects both types of transition in loneliness and spouse's functional limitation affects transition into loneliness through spouse's emotional health. In addition, for married men, their own functional limitation is significantly associated with their transitions into and out of loneliness. For married women, their spouse's functional limitation is significantly associated with their transition into loneliness and this is mainly through its association with spouse's emotional health. Also, for married women, their spouse's emotional health is significantly associated with their transition out of loneliness. Social interventions to reduce feelings of loneliness need to take a couple approach and consider both spouses' health problems and how they may affect their daily activities and their interactions with each other and with others.
\end{abstract}

Keywords: own and spousal health; loneliness; gender; China

\section{Introduction}

Loneliness, also referred to as perceived social isolation, is a major risk factor for a variety of poor health and behavioural outcomes in older adults (National Academies of Sciences, Engineering, and Medicine, 2020). Recent longitudinal research has demonstrated that loneliness in older Chinese adults predicts poor self-rated health, depressive symptoms, functional limitations, impaired cognition, unrestricted re-use, distribution, and reproduction in any medium, provided the original work is properly cited. 
frailty transition, grip strength decline, reductions in social activity participation and physical exercise, and increased mortality risk over time (Luo and Waite, 2014; Zhong et al., 2016; Sha et al., 2020; Yu et al., 2020). In addition, research has shown cross-sectional associations of loneliness with suicidal thoughts and attempts, more frequent health service utilisation, and greater vulnerability to fraud and abuse (Li et al., 2016; Zhang et al., 2018; Xing et al., 2020). In China, traditional cultural norms guided by Confucian philosophy and collectivism obligate children to take care of their ageing parents and intergenerational co-residence is a common way to provide instrumental and emotional support (Hsieh and Waite, 2019). However, the past four decades have seen drastic declines in fertility, changes in social attitudes and uneven rates of economic mobility, all of which have contributed to a rapid increase in the proportion of older adults who do not live with children (Zeng and Wang, 2003; Zhang, 2004). Although estimates varied greatly in part due to differences in whether regional or national samples were used and whether single-item questions or complex scales were used, recent studies indicated that both the prevalence of loneliness and levels of loneliness among older Chinese adults have increased (Yang and Victor, 2008; Yan et al., 2014), particularly among empty nest older adults (Chen et al., 2014). Given the increase in its prevalence and its devastating health impacts, loneliness among older Chinese adults requires rigorous investigation, and gaining a broad understanding of risk factors for loneliness can lead to more effective interventions to improve older adults' health and wellbeing.

Having a spouse has been consistently found to be a protective factor for loneliness and this is also the case in China (Chen et al., 2014). However, not all marriages are equal and poor-quality marriages have been associated with higher levels of loneliness for the spouses (Hawkley et al., 2008; Stokes, 2017). Older Chinese adults in need of help often turn to their spouse first, followed by their children (Chen et al., 2014). With declining support from adult children due to changing living arrangements, social support from a spouse has become increasingly important for the wellbeing of married older adults (You et al., 2020). This could be very challenging when either one or both spouses have major health problems and could lead to feelings of loneliness. Traditional Chinese culture discourages divorce or separation (Yan et al., 2014). Because married couples in China are less likely to end their marriage when they or their spouse have health problems compared to their Western counterparts, a larger proportion of married older Chinese adults would potentially have poor health conditions. In developing countries like China, spousal illness may be more stressful as the burden of care for an ill spouse falls more heavily on the other spouse (You et al., 2020) and the loss of income from job loss could have more devastating effects on daily life and family wellbeing (Howell and Howell, 2008). The lack of ability to end an unfulfilling marriage due to cultural sanction against divorce could also exert a psychological toll on an individual and further exacerbate the impact of a spouse's poor health (Miller et al., 2013).

In addition, China has a deep-rooted patriarchal tradition which has shaped men's and women's behaviours for more than a thousand years, and this has resulted in gendered care-giving experience which is perhaps stronger than in the West (Wong et al., 2019). Throughout their lifetime, women tend to devote 
more time to housework and care-giving and men tend to be the breadwinner of the family. Such gendered roles and expectations may also result in gender differences in family interactions and social relationships, which may ultimately lead to gendered loneliness experience in old age (Dong and Chen, 2017).

Most research on the health and loneliness relationship has focused on the association between individuals' own health and loneliness with little attention to the effects of spousal health on feelings of loneliness, even though there is strong evidence that caring for a spouse with poor health is a risk factor for one's own health and wellbeing (Meyler et al., 2007). A few studies on the effects of spousal health on loneliness used cross-sectional data (Korporaal et al., 2008), and to our best knowledge, no studies have examined the relationship between spousal health and loneliness in China and whether this relationship varies by gender. This study intends to fill these gaps by examining whether both own health and spousal health statuses affect transitions into and out of loneliness among middle-aged and older Chinese adults, and whether there are gender variations in these effects using data from a longitudinal national representative sample of middle-aged and older adults in China.

\section{Effects of own and spousal health on transitions in loneliness}

According to the stress process theory, negative impact of chronic stressors may constrain social interaction and threaten performance of social roles (Pearlin et al., 2005). One's own health may affect loneliness because health problems may act as chronic stressors and restrict individuals' ability to maintain quality social relationships and engage in social activities (Zimmer et al., 1997; Duke et al., 2002). Chronic illness is associated with emotional or psychological issues, mobility limitations, limited transportation or employment options, and strained social relationships (Warner et al., 2017). Individuals with functional impairment face similar challenges that leave them susceptible to being socially isolated or lonely (Warner and Adams, 2016). Depression-related cognitive biases can lead to negative appraisal and experience of social interactions (Burholt and Scharf, 2014). These physical and mental problems may also make individuals unpleasant social partners, discourage social connections and further complicate the maintenance of beneficial social interactions which often result in feelings of loneliness (Hsieh and Waite, 2019). A growing body of longitudinal studies have found that poor physical and mental health predicts increases in levels of loneliness over time (e.g. Luo et al., 2012; Hawkley and Kocherginsky, 2017; Dahlberg et al., 2018). Among older Chinese adults, emotional health, self-rated health and functional limitations predict incidence of loneliness in a three-year period (Yang and $\mathrm{Gu}, 2020$ ) and they predict increases in levels of loneliness over time, even after controlling for the reciprocal effects of loneliness on these health outcomes (Luo and Waite, 2014).

Spousal health may also affect loneliness in a number of ways. When the spouse has health problems, the healthy spouse may need to provide care ranging from helping with routine chores to full-time intensive care-giving, which reduces his or her availability for other social interactions (Wong and Hsieh, 2019). Care-givers also commonly suffer from physical issues such as illness, loss of 
appetite or sleep, or exhaustion, as well as mental health issues which further limit their ability to maintain relationships with friends and participate in social activities (Li et al., 2013). In addition, declines in either spouse's health can cause stressful marital interactions, such as shifts in power, division of labour, leisure time use, allocation of personal and financial resources, and risky health behaviours, all of which could lead to declining marital quality (Booth and Johnson, 1994; Wickrama et al., 2013; Galinsky and Waite, 2014). Because marital quality may be particularly important in later life as health tends to decline and the effects of adversity accumulate (Henry et al., 2007; Yorgason et al., 2008), older adults are more likely to feel lonely when they are not satisfied with the emotional, instrumental or sexual aspects of their marriage (Hawkley et al., 2008; Stokes, 2017). Furthermore, spouse's poor health status can produce stress or negative psychological outcomes for an older adult, even if that older adult is not the primary caregiver of the ill spouse, because one may feel sadness over the spouse's condition, fear of the loss of a companion or frustrated with how the family is responding (Amirkhanyan and Wolf, 2003; Freedman et al., 2014).

A sizeable literature has shown that not only older adults' own health but the health of their spouse is associated with their physical and emotional wellbeing, including their self-rated physical health (Valle et al., 2013), functional limitations (Strawbridge et al., 2007), chronic conditions (Chiu and Lin, 2019) and depressive symptoms (Siegel et al., 2004; Zivin and Christakis, 2007). An important line of research has examined spousal care-giving and loneliness among care-givers of chronically ill patients and found loneliness is more prevalent among spousal caregivers than non-care-givers (Li et al., 2013; Victor et al., 2021). There is also some evidence that spousal health is associated with older adults' feelings of loneliness. For example, spousal disability was found to be associated with higher levels of loneliness among a Dutch community sample of married adults aged 65 and older (Korporaal et al., 2008). Based on this literature, this study tests the following hypothesis:

(1) Older Chinese adults are more likely to transition into loneliness and less likely to transition out of loneliness over time if they or their spouses have poorer health.

\section{Gender, own and spousal health, and transitions in loneliness}

Although own health problems and spousal health problems are chronic stressors for both spouses, the stress process theory suggests that their effects on loneliness may differ for men and women as men and women are socialised into different roles and subject to different expectations, and within marriage they have access to different resources, confront different constraints and often have dissimilar experiences (Moen, 2001; Pearlin et al., 2005). Women can be expected to be more strongly affected by their own health and their spouse's health for several reasons (Korporaal et al., 2008; Warner and Kelley-Moore, 2012; Wong and Hsieh, 2019). First, women are socialised to be nurturing and family oriented, and they play a larger role in shaping and maintaining kinship and friendship relationships than men (Dykstra and De Jong Gierveld, 2004). Additionally, while men tend to 
derive social support primarily from their spouse, women derive more support and protection from loneliness from a larger network of family, friends and neighbours in addition to their spouse (Fuhrer and Stansfeld, 2002; Dykstra and De Jong Gierveld, 2004). Because of the greater needs for women to maintain social relationships, they may be more affected by their own and their spouse's health problems. Second, women have been found to be more sensitive to marital quality than men and poor marital quality has a stronger impact on women's health and wellbeing (Liu and Waite, 2014; Hsieh and Hawkley, 2017). Third, female caregivers experience higher levels of care-giving burden and feel more distressed than male care-givers because of gender differences in role commitment, emotional attentiveness and coping styles (Pinquart and Sörensen, 2006). Compared to male care-givers, female spousal care-givers reported greater involvement in the care of their ill spouse and have higher expectations in the quality of their care; they are more attentive to their emotions; and whereas men are more likely to use problem-focused and rational coping strategies, women are more inclined to adopt emotion-focused and avoidance coping strategies (Miller and Cafasso, 1992; Matud, 2004). Therefore, it can be hypothesised that:

(2) Transitions in loneliness are more strongly affected by own and spouse's health statuses among older Chinese women than older Chinese men.

\section{Methods}

\section{Data}

Data for this study came from three waves of the China Health and Retirement Longitudinal Study (CHARLS 2011-2015), conducted by the Peking University in China in collaboration with the University of Oxford and the University of Southern California. CHARLS is designed as a part of a set of longitudinal ageing surveys that include the Health and Retirement Study in the United States of America, the Survey of Health and Retirement in Europe, and similar longitudinal ageing surveys in other countries. The CHARLS survey instruments were designed to mirror the longitudinal ageing surveys used in other countries. CHARLS included computer-assisted in-person interviews with a nationally representative sample of adults aged 45 years and older, as well as their spouses when possible. The sample was obtained through four-stage stratified sampling, with an overall response rate of 80.5 per cent at the baseline (Zhao et al., 2014). The baseline survey was conducted between June 2011 and March 2012 covering 28 provinces, 150 counties/districts, 450 communities, 17,708 respondents from 10,257 households. Two follow-up interviews were conducted in 2013 and 2015. This study restricted the analysis to the 13,060 respondents who were aged 45 and older, married with a spouse who was also interviewed in 2011, and not missing on the loneliness question in 2011. Please note that due to these restrictions, some married households had only one eligible respondent for this study because the other spouse was aged below 45 even though both spouses were interviewed. Further restricted to the respondents who did not become a widow between interviews, the final analytical sample included 12,813 respondents (6,422 men and 6,391 women). Among them 11,333 were re-interviewed in 2013, and 10,925 were re-interviewed in 
2015. In the regression analyses, this study used the multiple imputation method for missing data that were caused by item non-response and lost to follow-ups (see below for details).

\section{Measures}

\section{Transitions in loneliness}

Transitions in loneliness indicate changes in feelings of loneliness in a two-year period. In the literature, loneliness is commonly measured either using a single direct question such as 'How often do you feel lonely?' or multi-item instruments which do not include the term 'lonely' or 'loneliness'. There have been some concerns that self-report of an undesirable emotional state with a single item may lead to underestimates of the true prevalence of loneliness (Cohen-Mansfield et al., 2016). This may also result in bias as loneliness is less common among married people than among widows and widowers, and thus loneliness may be considered more undesirable for married people than for widows and widowers. For this reason, it is possible that a married person is less likely to report his or her loneliness in response to a direct question although this supposition has not been substantiated by empirical research. Also, a single question is an instrument with an unknown and probably poor reliability (Cohen-Mansfield et al., 2016). Moreover, a single-question instrument cannot distinguish different dimensions of loneliness, such as social loneliness (lack of an engaging broader social network) versus emotional loneliness (absence of an intimate or close emotional attachment, such as a partner and a best friend) (De Jong Gierveld et al., 2006). Despite these limitations, the single-question measure of loneliness has been widely used and has been reported to have good face and predictive validity (Yang and Victor, 2008; Luo and Waite, 2014). In addition, this single-question measure was the original standard against which multi-item instruments were validated and it has been shown to be highly correlated with the two most widely used loneliness assessment tools, the UCLA Loneliness Scale (Russell, 1996) and the De Jong Gierveld Loneliness Scale (De Jong Gierveld and Van Tilburg, 1999). Furthermore, those indirect questions which assess the lack of support that may lead to loneliness might be confounded with social support itself (Bell and Gonzalez, 1988).

In CHARLS, loneliness was measured in all three waves with a single question asking how often the respondent felt lonely in the past week. The four-point response scale ranged from 'rare or none of the time $(<1$ day)' to 'most or all of the time (5-7 days)'. Because the question on loneliness in CHARLS is highly skewed with fewer respondents in the 'some', 'moderate' and 'most or all' categories, these three categories were combined into one to create a dichotomous indicator of loneliness status at each wave and then this categorisation was used to define transitions into and out of loneliness between waves.

\section{Respondent's own and spouse's health statuses}

Because CHARLS interviewed both spouses, chronic conditions, functional limitations and depressive symptoms in 2011 and 2013 for both respondents and their spouses were included. 
Chronic conditions. This is a count of positive responses to questions regarding whether or not a doctor has told the respondent that he or she had specific medical conditions, including hypertension, dyslipidemia, diabetes, cancer, lung disease, liver disease, heart problems, stroke, kidney disease, stomach disease, memory-related disease and asthma.

Functional limitations. The number of functional limitations was calculated by counting the number of times the respondent reported having some difficulty with or could not do seven activities, including specific forms of ambulation, such as walking 1 kilometre and climbing several flights of stairs without resting, or muscle movements, such as lifting or carrying weights over 10 Jin (5 kilograms) or picking up a small corn from a table. It ranged from 0 to 7 (Cronbach's $\alpha=0.82$ in 2011 and 0.80 in 2013).

Depressive symptoms. CHARLS includes a short version of the Center for Epidemiologic Studies Depression Scale (CES-D). Each item asked how often the respondent experienced a specific symptom in the past week ('bothered by things that don't usually bother me', 'had trouble keeping mind on what I was doing', 'depressed', 'everything I did was an effort', 'hopeful about the future', 'fearful', 'sleep was restless', 'happy', 'lonely' and 'could not get going') with the four-point response scale ranging from 'rare or none of the time ( $<1$ day)' to 'most or all of the time (5-7 days)'. Depression is conceptually related to but distinct from loneliness (Cacioppo et al., 2010). To reduce the overlap in measurement of the two concepts, the item in the CES-D that states 'I felt lonely' was excluded from the depressive symptoms scale. The average score of the remaining nine items, with two items tapping positive affect reverse coded, was used to measure depressive symptoms which ranged from 0 to 3 with higher scores indicating more depressive symptoms (Cronbach's $\alpha=0.79$ in 2011 and 0.73 in 2013).

\section{Social engagement}

This study included measures of social engagement in 2011 and 2013, such as work status, social activity participation, informal helping, caring for grandchildren and caring for spouse, which may explain the relationship between respondent's and spouse's health and loneliness.

Work status. Respondents who were working at the time of interview were compared with those who were not working.

Social activity participation. Respondents were asked whether they participated in six social activities in the previous month: interacted with friend; played mahjong, chess, cards or went to a community club; went to a sporting event, participated in a social group or participated in some other sort of club; took part in a community-related organisation; took part in voluntary or charity work; attended an educational or training course. Because the time-frame was one month, most of these activities had a low participation rate $(0.4-35 \%)$, thus social activity participation was measured with a dichotomous variable and respondents who had an affirmative answer to any of these questions were considered to have social activity 
participation. Using a summary score of the types of social activity in which an older adult participated instead of a dichotomised measure produced similar results.

Informal helping. Respondents were asked whether they provided help to family, friends or neighbours who did not live with them and whether they cared for a sick or disabled adult who did not live with them without being paid in the previous month. Respondents who had an affirmative answer to either question were considered as having provided informal help.

Grandchild care. The respondent's grandchild care-giving status in the past year had three categories: having grandchildren, but not providing any care; providing care; and no grandchildren.

Caring for spouse. In CHARLS respondents who reported difficulty in managing any activities of daily living (ADLs) or instrumental ADLs (IADLs) were asked who helped them with these difficulties. If the spouse was reported as the primary helper, the spouse of this respondent was considered to be a spouse care-giver.

\section{Socio-demographic covariates}

This study included gender, age in years at baseline survey, urban/rural residence, educational levels (illiterate, primary education, secondary education and above), and household expenditure as control variables. Household expenditures in 2011 and 2013 were included in this analysis. This study used the annual total household expenditure which was shown to be a better measure of economic resources available to the family than income in developing countries (Strauss and Thomas, 2007). CHARLS asked about food expenditures in the prior week, seven types of non-food expenditures in the past 30 days (e.g. communication fees, utilities, fuels) and 13 types of other non-food expenditures in the past year (e.g. clothing, heating, furniture). The total annual household expenditure was the sum of these expenditures, with weekly food expenditures and monthly non-food expenditures converted to annual amounts first, and it was log transformed because it was positively skewed.

\section{Statistical analysis}

Descriptive statistics for all respondents, and then stratified by gender, were calculated. To test whether gender differences were statistically significant, a $t$-test for continuous variables and a chi-square test for categorical variables were used. This study used a two-year interval dataset in which the unit of observation was the two-year interval between pairs of interviews (i.e. 2011-2013, 2013-2015) to assess the effects of spouses' health on transitions in loneliness over a two-year period. This dataset was created by combining two separate datasets with one containing 2011 and 2013 waves and the other containing 2013 and 2015 waves. The first dataset included variables in 2011 as Time 1 variables and variables in 2013 as Time 2 variables; the second dataset included variables in 2013 as Time 1 variables and variables in 2015 as Time 2 variables. The two datasets were pooled together so that data from the three waves of CHARLS could be fully utilised and it also helped increase the sample size 
for analysis of transitions in loneliness. Preliminary analyses tested whether pooling two separate two-year interval datasets was valid by including interactions of an interval indicator and measures of health statuses, and these interaction terms were not jointly significant, indicating that pooling was legitimate.

Because this study focuses on transition into loneliness between Time 1 and Time 2 among respondents who did not feel lonely at Time 1, and on transition out of loneliness between Time 1 and Time 2 among respondents who felt lonely at Time 1, binary logistic regressions were used to examine the effects of both spouses' health statuses on these transitions. Additional analysis using multinomial logistic regression produced similar results. This study estimated three models for each loneliness transition outcome. The first model included measures of respondents' health and demographic covariates to see whether respondents' own health is associated with transitions in loneliness net of demographic covariates. The second model added measures of spouses' health to test the effects of spouses' health after controlling for respondents' own health and demographic covariates. The third model added measures of social engagement to see whether the relationship between both spouses' health statuses and transitions in loneliness remain significant after accounting for their joint effects with social engagement. These models were estimated using Stata version 14.2 (StataCorp, College Station, TX). All analyses were done first for all eligible respondents and then for men and women separately. Gender differences in the coefficients were tested using the Seemingly Unrelated Estimation (suest) procedure.

These models were estimated with the Huber-White variance estimator to ensure that clustering in the sample (due to sample design and the use of multiple intervals per person) does not inflate test statistics. A dummy variable indicating the calendar year in which each interval began was also included in the models. To test whether the correlation at the household level may affect the estimates since both age-eligible respondents and their spouses were included in the model for all respondents, a multilevel logistic regression model which took into account the nesting of individuals within households was also estimated for each loneliness transition outcome and the results were similar to those reported in this paper.

One common problem in longitudinal studies is that attrition from the baseline to the follow-up surveys and missing cases on study variables do not occur completely at random. Preliminary analysis revealed that males, older age, more functional limitations, more chronic conditions, higher levels of depressive symptoms, having a spouse with fewer chronic conditions, not caring for spouse and not working were associated with higher mortality risk, and younger age, urban residence, higher household expenditures, fewer chronic conditions, not working, not helping and not caring for grandchildren were associated with higher probability of loss to follow-up. Thus, this study used multiple imputation with chained equations, which employed different regressions to impute different types of variables to replace those missing cases. Self-rated physical health and self-rated memory were included as auxiliary variables and ten imputed datasets were created to adjust for the potential bias. The imputed datasets were analysed separately and the results were combined in a way that accounted for variations in the imputed values (Allison, 2001; Young and Johnson, 2015). Regression models without imputing values for attrition and missing cases produced similar results. 


\section{Results}

\section{Descriptive statistics}

Table 1 reports descriptive statistics. The proportion of respondents who reported feeling lonely in the prior week fluctuated during the four-year study period. In 2011, about 26 per cent of respondents reported feeling lonely, and this number dropped to about 19 per cent in 2013 and then climbed back to nearly 23 per cent in 2015. In all three waves, women reported a higher prevalence rate of loneliness than men. At the baseline survey in 2011, the respondents had an average of 1.08 chronic conditions, 1.29 functional limitations and 0.86 on the depression scale ranging from 0 to 3 . While the depression scale slightly decreased from 2011 to 2013, the number of chronic conditions and functional limitations increased. Married women had more chronic conditions, more functional limitations and higher levels of depressive symptoms than married men.

At the baseline survey, 47 per cent of respondents participated in social activities. A higher proportion of married women provided care to grandchildren than married men (36\% versus $24 \%$ ). A higher proportion of married men than married women were working (76\% versus 67\%), provided informal care to relatives and friends ( $8 \%$ versus $7 \%$ ), and provided spousal care (11\% versus $9 \%)$. In addition, married men were older and had more education than married women.

\section{Own and spousal health statuses and transition into loneliness}

Of the 7,824 respondents who did not feel lonely in $2011,1,142$ (15\%) felt lonely in 2013 , and of the 7,117 respondents who did not feel lonely in 2013, 1,269 (18\%) felt lonely in 2015. Results from logistic regressions on transition into loneliness are shown in Table 2. When all respondents were included and controlling for sociodemographic characteristics, one additional chronic condition, one additional functional limitation and a one-point increase in the depressive symptoms scale increased the odds of becoming lonely by 12, 5 and 106 per cent, respectively, over a two-year period (Table 2, 'All', Model 1). When measures of spouse's health were added in Model 2 , a test of the joint effects of these spousal health measures showed that the model fit significantly improved over Model $1(p<0.001)$. Among them, spouse's level of depressive symptoms had a significant independent effect and a one-point increase in the spouse's depressive symptoms scale increased the respondent's odds of becoming lonely by 23 per cent. Additional analysis showed that spouse's number of functional limitations was also significantly associated with transition into loneliness (odds ratio $(\mathrm{OR})=1.06)$, but this association became non-significant after the spouse's level of depressive symptoms was added (not shown in the table). The effects of respondent's own health measures all remained significant in Model 2 with only the effect of depressive symptoms having a substantive attenuation $(\mathrm{OR}=1.91)$.

The associations between respondent's and spouse's physical and emotional health statuses and transition into loneliness did not change substantially when social engagement measures were added in Model 3. Caring for grandchildren was a significant predictor of transition from not feeling lonely to feeling lonely and social activity participation had a marginally significant effect $(p<0.1)$. Caring for grandchildren and social activity participation decreased the odds of becoming lonely by approximately 13 and 8 per cent, respectively. 
Table 1. Descriptive statistics

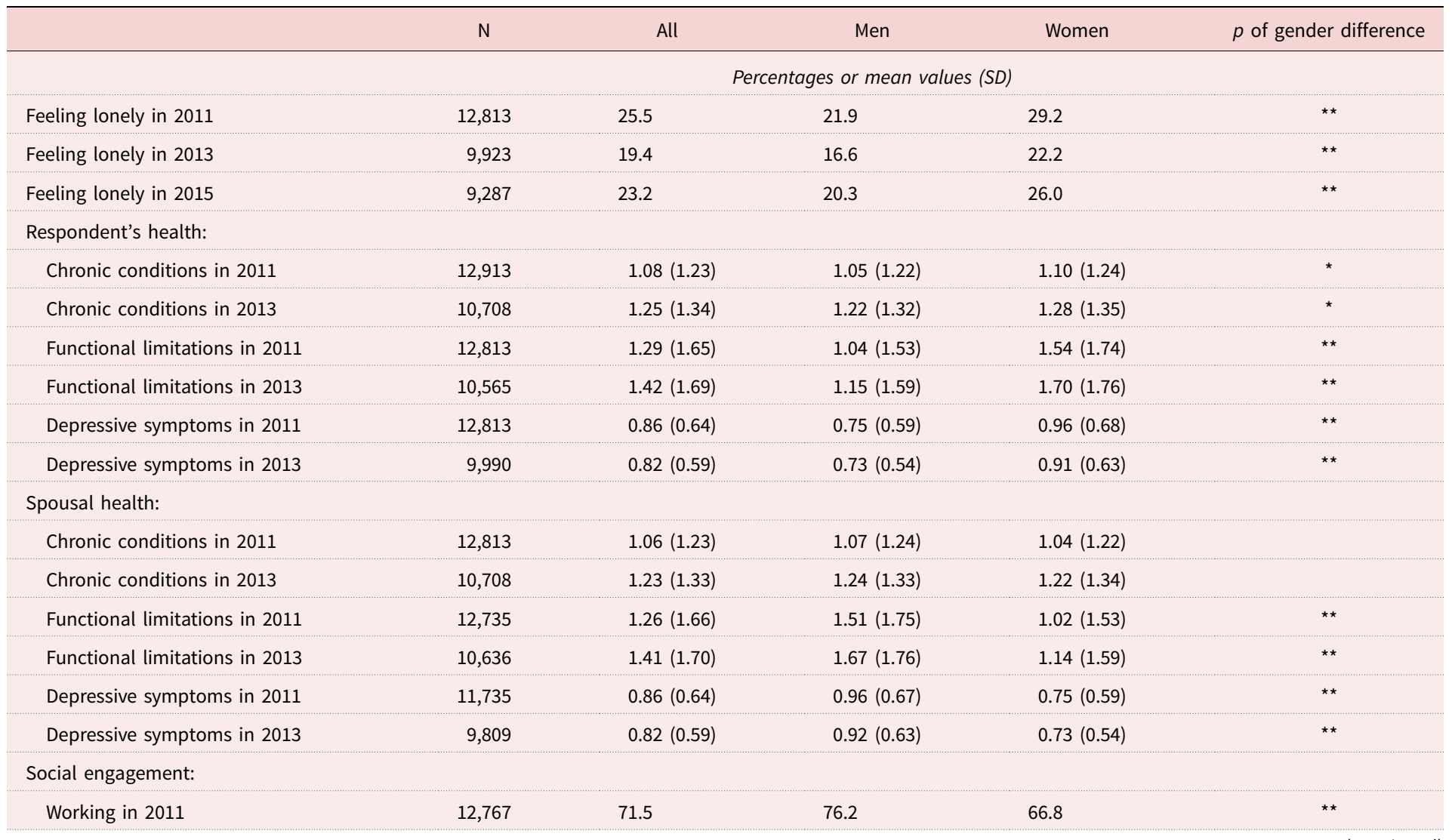


Table 1. (Continued.)

\begin{tabular}{|c|c|c|c|c|c|}
\hline & $\mathrm{N}$ & All & Men & Women & $p$ of gender difference \\
\hline Working in 2013 & 10,619 & 71.0 & 75.7 & 66.1 & ** \\
\hline Social activity participation in 2011 & 12,806 & 46.7 & 47.3 & 46.1 & \\
\hline Social activity participation in 2013 & 10,082 & 51.9 & 52.9 & 51.0 & \\
\hline Informal helping in 2011 & 12,811 & 7.5 & 8.2 & 6.7 & $\star \star$ \\
\hline Informal helping in 2013 & 10,082 & 14.2 & 14.8 & 13.5 & \\
\hline Grandchild care in 2011: & 12,813 & & & & $\star \star *$ \\
\hline No & & 39.2 & 41.6 & 36.9 & \\
\hline Yes & & 26.9 & 23.7 & 30.2 & \\
\hline No grandchildren & & 33.8 & 34.7 & 32.9 & \\
\hline Grandchild care in 2013: & 10,708 & & & & $\star \star$ \\
\hline No & & 41.2 & 43.6 & 38.6 & \\
\hline Yes & & 37.3 & 33.9 & 40.8 & \\
\hline No grandchildren & & 21.6 & 22.5 & 20.6 & \\
\hline Spousal care in 2011 & 12,813 & 10.1 & 10.9 & 9.4 & $\star *$ \\
\hline Spousal care in 2013 & 10,708 & 16.9 & 19.7 & 14.1 & $\star \star$ \\
\hline \multicolumn{6}{|l|}{ Demographics: } \\
\hline Female & 12,813 & 49.9 & & & \\
\hline Age in 2011 & 12,813 & $57.83(8.86)$ & $58.89(9.18)$ & $56.76(8.39)$ & ** \\
\hline Urban in 2011 & 12,813 & 39.6 & 39.6 & 39.5 & \\
\hline
\end{tabular}




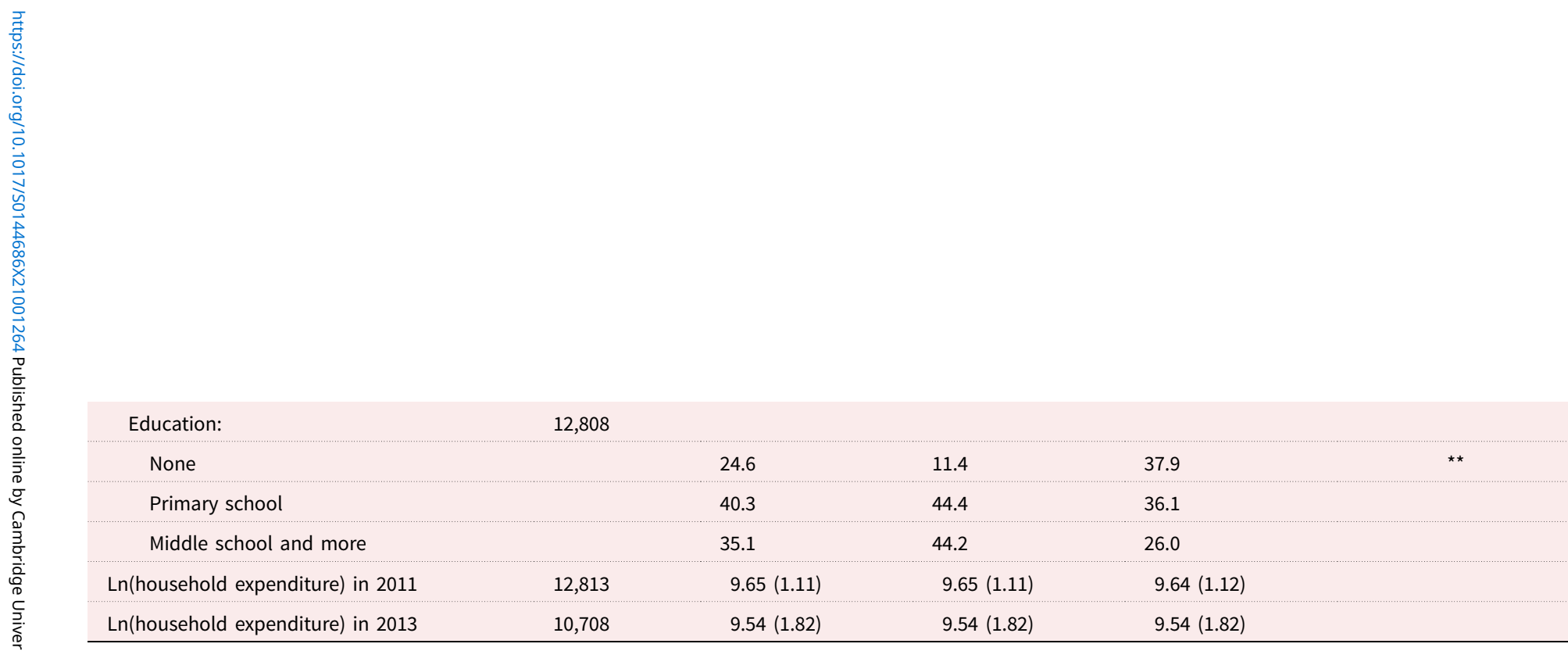

Note: SD: standard deviation.

Source: China Health and Retirement Longitudinal Study (2011-2015).

Significance levels: ${ }^{*} p<0.05,{ }^{\star \star} p<0.01$ (two-tailed tests). 
Table 2. Odds ratios from logistic regressions of transition from not feeling lonely to feeling lonely between Time 1 (T1) and Time 2 among respondents who did not feel lonely at $\mathrm{T} 1$

\begin{tabular}{|c|c|c|c|c|c|c|c|c|c|}
\hline \multirow[b]{2}{*}{ Variables } & \multicolumn{3}{|c|}{ All } & \multicolumn{3}{|c|}{ Men } & \multicolumn{3}{|c|}{ Women } \\
\hline & Model 1 & Model 2 & Model 3 & Model 1 & Model 2 & Model 3 & Model 1 & Model 2 & Model 3 \\
\hline Female & $(1.27)$ & $(2.42)$ & $(2.60)$ & & & & & & \\
\hline Age in 2011 & $0.99^{\star \star}$ & $0.99^{\star \star}$ & $0.99^{\star \star}$ & $0.99^{*}$ & $0.99^{\star}$ & $0.99^{*}$ & $0.99^{\star}$ & $0.99^{\star \star}$ & $0.99^{* *}$ \\
\hline Urban in 2011 & (5.19) & $(4.79)$ & $(4.73)$ & $(4.35)$ & (4.02) & $(4.20)$ & $(3.20)$ & $(3.02)$ & $(2.68)$ \\
\hline \multirow[t]{2}{*}{ Primary education (Ref. No education) } & $0.82^{\star \star}$ & $0.82^{\star \star}$ & $0.83^{\star \star}$ & 0.87 & 0.86 & 0.87 & $0.78^{\star \star}$ & $0.79^{\star \star}$ & $0.79^{* *}$ \\
\hline & $(3.37)$ & $(3.37)$ & $(3.32)$ & $(1.30)$ & $(1.36)$ & $(1.27)$ & $(3.47)$ & $(3.39)$ & $(3.39)$ \\
\hline $\begin{array}{l}\text { Middle school and more (Ref. No } \\
\text { education) }\end{array}$ & $0.70^{\star *}$ & $0.70^{* *}$ & $0.70^{\star \star}$ & $0.69^{\star *}$ & $0.69^{\star \star}$ & $0.69^{\star *}$ & $0.73^{\star *}$ & $0.73^{\star *}$ & $0.72^{\star \star}$ \\
\hline \multirow{2}{*}{$\begin{array}{l}\text { 2013-2015 interval (Ref. 2011-2013 } \\
\text { interval) }\end{array}$} & $1.26^{\star \star}$ & $1.27^{\star \star}$ & $1.30^{\star \star}$ & $1.24^{\star \star}$ & $1.25^{\star \star}$ & $1.28^{\star \star}$ & $1.29^{\star \star}$ & $1.29^{\star \star}$ & $1.32^{\star *}$ \\
\hline & $(5.05)$ & $(5.05)$ & $(5.40)$ & (3.33) & $(3.43)$ & (3.73) & (3.78) & $(3.73)$ & $(4.00)$ \\
\hline \multirow[t]{2}{*}{ Own chronic conditions at $\mathrm{T} 1$} & $1.12^{\star \star}$ & $1.11^{\star \star}$ & $1.12^{\star *}$ & $1.11^{\star \star}$ & $1.12^{\star \star}$ & $1.11^{\star \star}$ & $1.13^{\star \star}$ & $1.12^{\star \star}$ & $1.13^{\star \star}$ \\
\hline & $(5.73)$ & $(5.68)$ & $(5.83)$ & (3.56) & $(3.52)$ & (3.63) & (4.38) & $(4.30)$ & $(4.49)$ \\
\hline \multirow[t]{2}{*}{ Own functional limitations at $\mathrm{T} 1$} & $1.05^{\star \star}$ & $1.05^{\star \star}$ & $1.05^{\star \star}$ & $1.07^{\star \star}$ & $1.06^{\star}$ & $1.06^{\star}$ & 1.04 & 1.04 & 1.04 \\
\hline & (3.27) & (2.93) & $(2.87)$ & $(2.68)$ & $(2.46)$ & $(2.23)$ & $(1.86)$ & $(1.59)$ & $(1.63)$ \\
\hline
\end{tabular}




\begin{tabular}{|c|c|c|c|c|c|c|c|c|c|}
\hline \multirow[t]{2}{*}{ Own depressive symptoms at $\mathrm{T} 1$} & $2.06^{\star \star}$ & $1.91^{\star \star}$ & $1.92^{\star \star}$ & $2.10^{\star \star}$ & $1.93^{\star \star}$ & $1.92^{\star \star}$ & $2.04^{\star \star}$ & $1.91^{\star \star}$ & $1.92^{\star \star}$ \\
\hline & $(16.89)$ & $(14.54)$ & $(14.51)$ & $(11.62)$ & $(9.79)$ & $(9.76)$ & $(12.30)$ & $(10.60)$ & $(10.63)$ \\
\hline \multirow[t]{2}{*}{ Spouse chronic conditions at $\mathrm{T} 1$} & & 1.02 & 1.02 & & 1.01 & 1.01 & & 1.03 & 1.03 \\
\hline & & $(1.03)$ & $(1.09)$ & & $(0.40)$ & (0.48) & & $(1.10)$ & $(1.18)$ \\
\hline \multirow[t]{2}{*}{ Spouse functional limitations at $\mathrm{T} 1$} & & 1.01 & 1.01 & & 0.99 & 1.00 & & 1.02 & 1.02 \\
\hline & & $(0.42)$ & $(0.45)$ & & $(0.26)$ & $(0.07)$ & & $(0.87)$ & $(0.62)$ \\
\hline \multirow[t]{2}{*}{ Spouse depressive symptoms at $\mathrm{T} 1$} & & $1.23^{\star *}$ & $1.24^{\star \star}$ & & $1.24^{\star \star}$ & $1.25^{\star \star}$ & & $1.22^{\star \star}$ & $1.22^{\star *}$ \\
\hline & & $(4.50)$ & $(4.50)$ & & $(3.53)$ & $(3.61)$ & & $(3.08)$ & $(2.98)$ \\
\hline \multirow[t]{2}{*}{ Working at T1 } & & & 1.01 & & & 0.96 & & & 1.06 \\
\hline & & & $(0.22)$ & & & $(0.47)$ & & & $(0.73)$ \\
\hline \multirow[t]{2}{*}{ Social activity participation at $\mathrm{T} 1$} & & & 0.92 & & & 0.89 & & & 0.95 \\
\hline & & & $(1.68)$ & & & $(1.57)$ & & & $(0.81)$ \\
\hline \multirow[t]{2}{*}{ Informal helping at $\mathrm{T} 1$} & & & 1.08 & & & 1.15 & & & 1.01 \\
\hline & & & $(1.06)$ & & & $(1.29)$ & & & $(0.10)$ \\
\hline \multirow[t]{2}{*}{ Caring for grandchildren (Ref. No care) } & & & $0.87^{\star \star}$ & & & 0.98 & & & $0.79^{\star *}$ \\
\hline & & & $(2.61)$ & & & $(0.20)$ & & & $(3.33)$ \\
\hline \multirow[t]{2}{*}{ No grandchildren (Ref. No care) } & & & 1.07 & & & 1.16 & & & 0.99 \\
\hline & & & $(1.21)$ & & & $(1.73)$ & & & $(0.15)$ \\
\hline \multirow[t]{2}{*}{ Caring for spouse } & & & 0.97 & & & 0.93 & & & 1.02 \\
\hline & & & $(0.38)$ & & & $(0.72)$ & & & $(0.19)$ \\
\hline \multirow[t]{2}{*}{ Constant } & $0.22^{\star \star}$ & $0.19^{\star \star}$ & $0.18^{\star *}$ & $0.19^{\star *}$ & $0.17^{\star \star}$ & $0.17^{\star \star}$ & $0.27^{\star \star}$ & $0.25^{\star \star}$ & $0.24^{\star *}$ \\
\hline & $(5.34)$ & (5.73) & (5.33) & (3.97) & $(4.24)$ & (3.83) & (3.55) & (3.67) & $(3.47)$ \\
\hline
\end{tabular}


Table 2. (Continued.)

\begin{tabular}{|c|c|c|c|c|c|c|c|c|c|}
\hline Variables & \multicolumn{3}{|c|}{ All } & \multicolumn{3}{|c|}{ Men } & \multicolumn{3}{|c|}{ Women } \\
\hline Number of individuals & 11,160 & 11,160 & 11,160 & 5,724 & 5,724 & 5,724 & 5,436 & 5,436 & 5,436 \\
\hline
\end{tabular}

Notes: Results are based on two-year interval data. Robust $z$-statistics are in parentheses. Ref.: reference category. Significance levels: * $p<0.05,{ }^{\star \star} p<0.01$ (two-tailed tests). 
For both married men and women, respondent's own number of chronic conditions and level of depressive symptoms were significantly associated with transition into loneliness (Table 2, 'Men' and 'Women', Model 1). The effect of functional limitations was only significant for married men. Spouse's health measures jointly significantly improved model fit for both men $(p<0.01)$ and women $(p<0.001)$ when they were added in Model 2, and spouse's level of depressive symptoms had a significant positive effect on transition into loneliness for both men and women. Additional analysis showed that only for women, spouse's number of functional limitations was significantly associated with transition into loneliness $(\mathrm{OR}=1.09)$ before spouse's level of depressive symptoms was taken into account (not shown in the table). For neither married men nor married women, the effects of respondent's own health and spouse's health statuses on transition into loneliness substantially decreased after measures of social engagement were added in Model 3. Caring for grandchildren was significantly associated with lower odds of transition into loneliness only for married women $(\mathrm{OR}=0.79)$. Tests of whether gender differences in the OR values were statistically significant indicated that there was a significant gender difference in the association between caring for grandchildren and transition into loneliness, but the associations between other variables and transition into loneliness were not significantly different between men and women.

\section{Own and spousal health statuses and transition out of loneliness}

Of the 2,659 respondents who felt lonely in 2011, 1,726 (65\%) did not feel lonely in 2013 and of the 1,707 respondents who felt lonely in 2013, 940 (55\%) did not feel lonely in 2015. Results from logistic regressions on transition out of loneliness are shown in Table 3 . When all respondents were included and controlling for sociodemographic characteristics, one additional chronic condition, one additional physical limitation and a one-point increase in the depressive symptoms scale decreased the odds of transition out of loneliness by 6,4 and 49 per cent, respectively, over a two-year period (Table 3, 'All', Model 1). These associations remained significant and largely unchanged after measures of spouse's health were added in Model 2. Spouse's health measures jointly significantly improved the model fit over Model $1(p<0.05)$. Among them, spouse's level of depressive symptoms had an independent significant effect and a one-point increase in the spouse's level of depressive symptoms decreased respondent's odds of transition out of loneliness by 16 per cent.

The associations between respondent's and spouse's health statuses and transition out of loneliness did not change substantially after social engagement measures were added in Model 3. Among social engagement measures, caring for grandchildren and caring for spouse were significantly associated with transition out of loneliness. While caring for grandchildren increased the odds of transition out of loneliness by 18 per cent, caring for a sick spouse decreased the odds of transition out of loneliness by 20 per cent.

For both married men and women, respondent's own level of depressive symptoms was associated with decreased odds of transition out of loneliness (Table 3, 'Men' and 'Women', Model 1). However, number of functional limitations was 
Table 3. Odds ratios from logistic regressions of transition from feeling lonely to not feeling lonely between Time 1 (T1) and Time 2 among respondents who felt lonely at $\mathrm{T} 1$

\begin{tabular}{|c|c|c|c|c|c|c|c|c|c|}
\hline \multirow[b]{2}{*}{ Variables } & \multicolumn{3}{|c|}{ All } & \multicolumn{3}{|c|}{ Men } & \multicolumn{3}{|c|}{ Women } \\
\hline & Model 1 & Model 2 & Model 3 & Model 1 & Model 2 & Model 3 & Model 1 & Model 2 & Model 3 \\
\hline Female & (0.06) & $(0.59)$ & $(0.68)$ & & & & & & \\
\hline Age in 2011 & 1.00 & 1.00 & 1.00 & 1.00 & 1.00 & 1.00 & 1.01 & 1.01 & 1.00 \\
\hline Urban in 2011 & $(0.76)$ & $(0.57)$ & $(0.21)$ & $(0.17)$ & $(0.19)$ & $(0.33)$ & $(1.09)$ & $(0.87)$ & $(0.63)$ \\
\hline \multirow[t]{2}{*}{ Primary education (Ref. No education) } & 1.04 & 1.03 & 1.04 & 1.03 & 1.03 & 1.04 & 1.03 & 1.01 & 1.03 \\
\hline & $(0.45)$ & $(0.39)$ & $(0.47)$ & $(0.16)$ & $(0.19)$ & $(0.24)$ & $(0.31)$ & $(0.14)$ & $(0.24)$ \\
\hline Middle school and more (Ref. No education) & 1.01 & 1.00 & 1.00 & 0.91 & 0.92 & 0.93 & 1.08 & 1.05 & 1.07 \\
\hline \multirow[t]{2}{*}{ 2013-2015 interval (Ref. 2011-2013 interval) } & $0.68^{\star \star}$ & $0.67^{\star *}$ & $0.67^{\star \star}$ & $0.62^{\star \star}$ & $0.62^{\star \star}$ & $0.61^{\star \star}$ & $0.71^{\star \star}$ & $0.71^{\star *}$ & $0.72^{\star \star}$ \\
\hline & (6.15) & (6.16) & $(5.95)$ & $(4.92)$ & $(4.90)$ & $(4.87)$ & $(4.01)$ & $(4.01)$ & $(3.75)$ \\
\hline \multirow[t]{2}{*}{ Own chronic conditions at $\mathrm{T} 1$} & $0.94^{\star}$ & $0.94^{*}$ & $0.94^{\star}$ & 0.94 & 0.94 & 0.94 & 0.95 & 0.95 & 0.94 \\
\hline & $(2.44)$ & $(2.43)$ & $(2.53)$ & $(1.83)$ & $(1.70)$ & $(1.78)$ & $(1.68)$ & $(1.75)$ & $(1.88)$ \\
\hline \multirow[t]{2}{*}{ Own functional limitations at $\mathrm{T} 1$} & $0.96^{\star}$ & $0.96^{\star}$ & $0.95^{\star}$ & $0.94^{*}$ & $0.93^{*}$ & $0.92^{*}$ & 0.97 & 0.97 & 0.97 \\
\hline & $(2.04)$ & $(2.00)$ & $(2.23)$ & $(2.07)$ & $(2.12)$ & (2.44) & $(1.16)$ & $(1.08)$ & $(1.24)$ \\
\hline
\end{tabular}




\begin{tabular}{|c|c|c|c|c|c|c|c|c|c|}
\hline \multirow[t]{2}{*}{ Own depressive symptoms at $\mathrm{T} 1$} & $0.51^{\star \star}$ & $0.54^{\star \star}$ & $0.53^{\star \star}$ & $0.47^{\star \star}$ & $0.49^{* *}$ & $0.48^{\star *}$ & $0.53^{\star \star}$ & $0.57^{\star \star}$ & $0.57^{\star \star}$ \\
\hline & $(12.66)$ & $(10.77)$ & $(10.75)$ & $(8.73)$ & $(7.96)$ & $(8.07)$ & $(9.10)$ & $(7.51)$ & $(7.40)$ \\
\hline \multirow[t]{2}{*}{ Spouse chronic conditions at $\mathrm{T} 1$} & & 0.98 & 0.99 & & 0.95 & 0.96 & & 1.00 & 1.01 \\
\hline & & $(0.70)$ & $(0.52)$ & & $(1.17)$ & $(1.12)$ & & $(0.03)$ & $(0.21)$ \\
\hline \multirow[t]{2}{*}{ Spouse functional limitations at $\mathrm{T} 1$} & & 1.02 & 1.03 & & 1.03 & 1.04 & & 1.00 & 1.02 \\
\hline & & $(0.71)$ & $(1.50)$ & & $(0.91)$ & $(1.26)$ & & $(0.02)$ & $(0.83)$ \\
\hline \multirow[t]{2}{*}{ Spouse depressive symptoms at $\mathrm{T} 1$} & & $0.84^{\star \star}$ & $0.85^{*}$ & & 0.92 & 0.93 & & $0.79^{\star \star}$ & $0.80^{\star}$ \\
\hline & & $(2.61)$ & $(2.40)$ & & $(0.92)$ & $(0.78)$ & & $(2.68)$ & (2.55) \\
\hline \multirow[t]{2}{*}{ Working at $\mathrm{T} 1$} & & & 0.88 & & & 0.81 & & & 0.91 \\
\hline & & & $(1.45)$ & & & $(1.48)$ & & & $(0.85)$ \\
\hline \multirow[t]{2}{*}{ Social activity participation at $\mathrm{T} 1$} & & & 0.95 & & & 0.85 & & & 1.03 \\
\hline & & & $(0.71)$ & & & $(1.42)$ & & & $(0.29)$ \\
\hline \multirow[t]{2}{*}{ Informal helping at $\mathrm{T} 1$} & & & 0.98 & & & 1.24 & & & 0.80 \\
\hline & & & $(0.15)$ & & & $(1.16)$ & & & (1.54) \\
\hline \multirow[t]{2}{*}{ Caring for grandchildren (Ref. No care) } & & & $1.18^{\star}$ & & & 1.20 & & & 1.15 \\
\hline & & & $(2.17)$ & & & $(1.44)$ & & & (1.38) \\
\hline \multirow[t]{2}{*}{ No grandchildren (Ref. No care) } & & & 1.00 & & & 0.99 & & & 0.98 \\
\hline & & & $(0.05)$ & & & $(0.05)$ & & & $(0.18)$ \\
\hline \multirow[t]{2}{*}{ Caring for spouse } & & & $0.80^{\star}$ & & & 0.84 & & & 0.77 \\
\hline & & & $(2.41)$ & & & $(1.26)$ & & & $(1.87)$ \\
\hline \multirow[t]{2}{*}{ Constant } & $3.51^{\star \star}$ & $3.99^{\star \star}$ & $5.06^{\star *}$ & $5.96^{\star \star}$ & $6.18^{\star *}$ & $8.97^{\star *}$ & 2.41 & $2.81^{*}$ & $3.26^{\star}$ \\
\hline & (3.20) & (3.48) & (3.73) & $(2.91)$ & (2.95) & (3.15) & (1.72) & $(1.96)$ & (2.10) \\
\hline
\end{tabular}


Table 3. (Continued.)

\begin{tabular}{|c|c|c|c|c|c|c|c|c|c|}
\hline Variables & \multicolumn{3}{|c|}{ All } & \multicolumn{3}{|c|}{ Men } & \multicolumn{3}{|c|}{ Women } \\
\hline Number of individuals & 4,341 & 4,341 & 4,341 & 1,891 & 1,891 & 1,891 & 2,450 & 2,450 & 2,450 \\
\hline
\end{tabular}

Notes: Results are based on two-year interval dataset. Robust $z$-statistics are in parentheses. Ref.: reference category. Significance levels: ${ }^{\star} p<0.05,{ }^{\star \star} p<0.01$ (two-tailed tests). 
associated only with men's transition out of loneliness $(\mathrm{OR}=0.94)$. For married men, spouse's health measures did not significantly improve the model fit when they were added in Model 2, and none of the spouse's health measures were significantly associated with the odds of transition out of loneliness. For married women, spouse's health measures jointly improved the model fit when they were added in Model $2(p<0.05)$ and spouse's level of depressive symptoms had a significantly independent negative association with this transition $(\mathrm{OR}=0.79)$.

For both married men and women, the associations between respondent's and spouse's health measures and odds of transition out of loneliness did not change substantially when social engagement measures were added in Model 3. Tests of gender differences in the OR values indicated that the associations between the variables in these models and transition out of loneliness were not significantly different between men and women.

\section{Discussion}

This study contributes to the literature on health and loneliness in several important ways.

First, this study used a large national sample of middle-aged and older adults in China with interviews of both spouses which allowed the generalisability of the relationship between health and loneliness beyond Western societies to be determined. Second, as reviewed earlier, previous literature suggests that for married couples, not only does an individual's own health matter for their wellbeing, but also their spouse's health. This study extended this line of research by examining the impact of both spouses' health characteristics on older adults' feelings of loneliness. Third, this study added to a growing body of literature which focused on transitions in loneliness over time and risk factors for these transitions.

The prevalence of loneliness in the study sample had a major decline from 2011 to 2013 though it climbed back from 2013 to 2015. A further analysis revealed that such changes also occurred when all respondents in each survey year, not just those who were married and were interviewed in the 2011 wave, were included, and they occurred in both weighted and unweighted data. In addition, levels of depressive symptoms and social activity participation showed similar changes. These findings suggest that such fluctuations in prevalence of loneliness cannot be fully explained by sample selection and measurement choices. In 2011, the China State Council published its 12th Five-year Plan of China on Ageing Undertaking Development and the Social Care Service System Construction Plan (2011-2015), and in late 2012, the Law on Protecting the Rights and Benefits of Older Persons of the People's Republic of China was revised and adopted by the People's Congress (Du, 2015). These laws and policies have led to a series of undertakings and programmes to strengthen health and social services to older adults which may have played a role in the decline of loneliness from 2011 to 2013. However, more research is needed to evaluate the long-term impact of these policy initiatives on loneliness and on older adults' wellbeing in general.

The first hypothesis that middle-aged and older Chinese adults are more likely to transition into loneliness and less likely to transition out of loneliness over time if they or their spouse have poorer health is supported by the data. The finding of a 
strong impact of older adults' own health on loneliness is consistent with other studies in China and in other countries, suggesting that the impact of health on loneliness is widespread across different societies. More importantly, this study found that independent of an individual's own health status, spouse's emotional health predicts both types of transition in loneliness and spouse's functional limitation predicts transition into loneliness through its effects on emotional health. This study is one of the few that focused on transitions in loneliness and it can be argued that spousal health may be more strongly associated with loneliness in China due to the continuation of poor quality marriages (related to the stigma attached to divorce) and the greater reliance on spouses for family economic wellbeing and for care-giving in China. However, research on older adults in other countries has also found an association between spousal health and marital quality (e.g. Booth and Johnson, 1994; Galinsky and Waite, 2014), between spousal health and individuals' own health and wellbeing (e.g. Zivin and Christakis, 2007; Valle et al., 2013), and between marital quality and loneliness (e.g. Hawkley et al., 2008; Stokes, 2017). Therefore, spousal health is likely to affect loneliness among older adults across different societies. Taken together, these findings suggest that we need to pay more attention to both spouses' health in married couples in order to combat feelings of loneliness and their negative impact on older people's lives.

There are mixed results on the second hypothesis that own health and spousal health statuses have stronger effects on transitions in loneliness for married women than for married men. As expected from gendered roles and expectations, only older Chinese women's transition into loneliness is significantly affected by their spouse's functional limitations and only older Chinese women's transition out of loneliness is significantly affected by their spouse's emotional health. However, the finding that the number of own functional limitations has a significant effect only on older Chinese men's transition into loneliness contradicts our hypothesis. Yang and $\mathrm{Gu}(2020)$ also found that IADL difficulty significantly predicted transition into loneliness only for older Chinese men, but self-rated health and psychological resilience were significantly associated with transition into loneliness only for older Chinese women. Their study, however, did not include spouse's health characteristics. In a study on the relationship between both spouses' disability and loneliness based on a Dutch community sample of older adults, Korporaal et al. (2008) found that for men, only their wives' disability was related to higher levels of social loneliness, whereas for women mainly their own disability was related to higher levels of social loneliness. Their study found no gender differences in the effects of own disability and spouse's disability on emotional loneliness. Although findings from the current study seem to suggest that the husband's health matters more for both spouses' loneliness in China which is consistent with China's patriarchal tradition, the inconsistent findings in these studies paint a more complex picture of the gender differences in the effects of spouses' health statuses on loneliness and underscore the need for more research in the future.

The results from this study also showed that the effects of own health and spousal health on transitions in loneliness are not explained away by social engagement. This finding is consistent with several studies on different populations which showed that socialising with friends and family, participating in community activities and social 
support all play a very small mediating role between poor health and psychological wellbeing (Korporaal et al., 2008; Warner and Adams, 2016; Hsieh and Waite, 2019). Also, only a few social engagement measures included in this study had significant effects on transitions in loneliness. It is possible that our measures of social engagement do not capture all types of social interactions undertaken by older adults or they are not sufficiently detailed to reflect various levels of engagement. In addition, it is possible that older adults' own health and their spouse's health are powerful predictors of loneliness beyond their impact on social engagement. Social engagement may help with social loneliness, but it may do little to reduce emotional loneliness that is characterised by intense feelings of emptiness and abandonment (De Jong Gierveld et al., 2006). Previous research suggests that sociodemographic and health factors diverge in their level of association with social loneliness and emotional loneliness, and there is some evidence that physical and psychological wellbeing is more strongly correlated with emotional loneliness than with social loneliness (Dahlberg and McKee, 2014; McHugh Power et al., 2020). Future research needs to focus more on identifying the mechanisms underlying these effects and differentiating the effects on social loneliness and those on emotional loneliness.

Middle-aged and older Chinese adults seem to benefit from caring for grandchildren and participation in social activities as this study found that those engaged in these activities are less likely to transition into and more likely to transition out of loneliness. However, caring for a sick spouse decreases the likelihood of transition out of loneliness. These findings highlight the need to separate obligatory activities and discretionary activities because their effects are likely to be different (Baltes et al., 1999). Obligatory activities, such as spousal care, can seldom be avoided within a marriage. They are imposed on the individual by economic, cultural or social demands, and thus they may negatively affect psychological wellbeing. Discretionary activities, such as exercise, entertainment, hobbies and socialising, are activities people pursue in their free time and at their own discretion for personal enjoyment, social interaction and community development. Thus, discretionary activities are more likely to have a positive impact on psychological wellbeing. The beneficial effect of caring for grandchildren for older Chinese women's wellbeing is consistent with other studies which suggests that caring for grandchildren might promote an active lifestyle in older adults and allow them to gain social support, especially emotional support, by engaging with others through social networks (Luo et al., 2019). It should be noted that societies differ in terms of what activities are obligatory and what activities are discretionary (Baltes et al., 1999), and such differences must be taken into account in order to gain a better understanding of the impact of specific activities on older adults' wellbeing.

This study has several limitations. First, loneliness is measured with a single item. As discussed earlier, although this single-question measure is considered as valid, it has its own limitations and may partially explain the fluctuating prevalence rate in the three waves of the CHARLS sample. Future research should compare findings using single-item versus composite measures. Second, with a single-item loneliness measure, this study did not differentiate social loneliness from emotional loneliness which previous research found are differently affected by spouses' health statuses (Korporaal et al., 2008). Third, CHARLS does not have direct measures of marital quality and marital interactions which may mediate the relationship 
between both spouses' health statuses and loneliness. Declines in health can act as a stressor that causes stressful interactions with spouses and poor relationship quality, which in turn may lead to higher levels of loneliness. Fourth, although this study showed that feelings of loneliness fluctuated over the four-year study period and a sizeable portion of older adults transitioned into and out of loneliness between waves, studies that follow the respondents over a longer period may provide a more complete picture of how feelings of loneliness change over time and how spouses' health statuses impact this change.

Overall, this study demonstrates that despite the cultural tradition that emphasises the family system and collectivism, feelings of loneliness are prevalent even among married older adults in contemporary China and both spouses' health statuses are related to transitions into and out of loneliness. These findings have important implications not only for older adults in China, but also for older adults in other countries. According to estimates from various countries, feelings of loneliness are more prevalent in later life, affecting between 20 and 45 per cent of older adults (Cohen-Mansfield et al., 2016). In the past several decades, many countries have experienced substantial increases in life expectancy which is accompanied by increases in the prevalence of chronic conditions, disability and cognitive impairment, and increases in health-care costs (Weeks, 2020). With these demographic changes, married couples are expected to live together for a longer time in old age and this also means that they live with more health problems from both spouses. Previous research has established a relationship between spousal health and older adults' own health, between spousal health and marital quality, and between marital quality and loneliness in more-developed countries. Future research, however, needs to examine more directly the relationship between spousal health and loneliness in these countries. In addition, future research needs to focus more on the mechanisms underlying the relationship between spouses' health statuses and loneliness and variations in this relationship by social and cultural factors in order to help develop concrete and effective strategies to improve older adults' wellbeing. Based on findings from this study, social interventions that aim to reduce feelings of loneliness need to take a couple approach when dealing with married older adults and consider both spouses' health problems and how these problems may affect their daily activities and their interactions with each other and with others. Such interventions are even more critical during the current COVID-19 pandemic when social distancing measures have been taken in many countries to contain the spread of the disease and families are relying more on those living in the same household, and for most families the spouse, for care and support.

Conflict of interest. The author declares no conflicts of interest.

Ethical standards. Ethical approval was not required for this study.

\section{References}

Allison PD (2001) Missing Data. Thousand Oaks, CA: Sage.

Amirkhanyan AA and Wolf DA (2003) Caregiver stress and noncaregiver stress: exploring the pathways of psychiatric morbidity. The Gerontologist 43, 817-827.

Baltes MM, Maas I, Wilms H-U, Borchelt M and Little T (1999) Everyday competence in old and very old age: theoretical considerations and empirical findings. In Baltes PB and Mayr KU (eds). The Berlin Aging Study: Aging from 70 to 100. New York, NY: Cambridge University Press, pp. 384-402. 
Bell RA and Gonzalez MC (1988) Loneliness, negative life events, and the provisions of social relationships. Communication Quarterly 36, 1-15.

Booth A and Johnson DR (1994) Declining health and marital quality. Journal of Marriage and the Family 56, 218-223.

Burholt V and Scharf T (2014) Poor health and loneliness in later life: the role of depressive symptoms, social resources, and rural environments. Journals of Gerontology: Psychological Sciences and Social Sciences 69B, 311-324.

Cacioppo JT, Hawkley LC and Thisted RA (2010) Perceived social isolation makes me sad: 5-year crosslagged analyses of loneliness and depressive symptomatology in the Chicago Health, Aging, and Social Relations Study. Psychology and Aging 25, 453-463.

Chen Y, Hicks A and While AE (2014) Loneliness and social support of older people in China: a systematic literature review. Health \& Social Care in the Community 22, 113-123.

Chiu C-J and Lin Y-C (2019) Spousal health and older adults' biomarker change over six years: investigation of gender differences. Archives of Gerontology and Geriatrics 83, 44-49.

Cohen-Mansfield J, Hazan H, Lerman Y and Shalom V (2016) Correlates and predictors of loneliness in older-adults: a review of quantitative results informed by qualitative insights. International Psychogeriatrics 28, 557-576.

Dahlberg L and McKee KJ (2014) Correlates of social and emotional loneliness in older people: evidence from an English community study. Aging \& Mental Health 18, 504-514.

Dahlberg L, Andersson L and Lennartsson C (2018) Long-term predictors of loneliness in old age: results of a 20-year national study. Aging \& Mental Health 22, 190-196.

De Jong Gierveld J and Van Tilburg T (1999) Living arrangements of older adults in the Netherlands and Italy: coresidence values and behaviour and their consequences for loneliness. Journal of Cross-cultural Gerontology 14, 1-24.

De Jong Gierveld J, Van Tilburg T and Dykstra PA (2006) Loneliness and social isolation. In Vangelisti A and Perlman D (eds), Cambridge Handbook of Personal Relationships. Cambridge: Cambridge University Press, pp. 485-500.

Dong X and Chen R (2017) Gender differences in the experience of loneliness in U.S. Chinese older adults. Journal of Women \& Aging 29, 115-125.

Du P (2015) Long term care for older persons in China. United Nations Economic and Social Commissions in Asia and the Pacific, Bangkok, SDD-SPPS Project Working Papers Series: Long-term Care for Older Persons in Asia and the Pacific.

Duke J, Leventhal H, Brownlee S and Leventhal EA (2002) Giving up and replacing activities in response to illness. Journals of Gerontology: Psychological Sciences and Social Sciences 57B, P367-P376.

Dykstra PA and De Jong Gierveld J (2004) Gender and marital-history differences in emotional and social loneliness among Dutch older adults. Canadian Journal on Aging 23, 141-155.

Freedman VA, Cornman JC and Carr D (2014) Is spousal caregiving associated with enhanced well-being? New evidence from the Panel Study of Income Dynamics. Journals of Gerontology: Psychological Sciences and Social Sciences 69B, 861-869.

Fuhrer R and Stansfeld SA (2002) How gender affects patterns of social relations and their impact on health: a comparison of one or multiple sources of support from 'close persons'. Social Science \& Medicine 54, 811-825.

Galinsky AM and Waite LJ (2014) Sexual activity and psychological health as mediators of the relationship between physical health and marital quality. Journals of Gerontology: Psychological Sciences and Social Sciences 69B, 482-492.

Hawkley LC and Kocherginsky M (2017) Transitions in loneliness among older adults: a 5-year follow-up in the National Social Life, Health, and Aging Project. Research on Aging 40, 365-387.

Hawkley LC, Hughes ME, Waite LJ, Masi CM, Thisted RA and Cacioppo JT (2008) From social structural factors to perceptions of relationship quality and loneliness: the Chicago Health, Aging, and Social Relations Study. Journals of Gerontology: Psychological Sciences and Social Sciences 63B, S375-S384.

Henry NJM, Berg CA, Smith TW and Florsheim P (2007) Positive and negative characteristics of marital interaction and their association with marital satisfaction in middle-aged and older couples. Psychology and Aging 22, 428-441.

Howell RT and Howell CJ (2008) The relation of economic status to subjective well-being in developing countries: a meta-analysis. Psychological Bulletin 134, 536-560. 
Hsieh N and Hawkley L (2017) Loneliness in the older adult marriage: associations with dyadic aversion, indifference, and ambivalence. Journal of Social and Personal Relationships 35, 1319-1339.

Hsieh N and Waite L (2019) Disability, psychological well-being, and social interaction in later life in China. Research on Aging 41, 362-389.

Korporaal M, Broese van Groenou MI and Van Tilburg TG (2008) Effects of own and spousal disability on loneliness among older adults. Journal of Aging and Health 20, 306-325.

Li QP, Mak YW and Loke AY (2013) Spouses' experience of caregiving for cancer patients: a literature review. International Nursing Review 60, 178-187.

Li H, Xu L and Chi I (2016) Factors related to Chinese older adults' suicidal thoughts and attempts. Aging \& Mental Health 20, 752-761.

Liu H and Waite L (2014) Bad marriage, broken heart? Age and gender differences in the link between marital quality and cardiovascular risks among older adults. Journal of Health and Social Behavior 55, 403-423.

Luo Y and Waite LJ (2014) Loneliness and mortality among older adults in China. Journals of Gerontology: Psychological Sciences and Social Sciences 69B, 633-645.

Luo Y, Hawkley LC, Waite LJ and Cacioppo JT (2012) Loneliness, health, and mortality in old age: a national longitudinal study. Social Science \& Medicine 74, 907-914.

Luo Y, Pan X and Zhang Z (2019) Productive activities and cognitive decline among older adults in China: evidence from the China Health and Retirement Longitudinal Study. Social Science \& Medicine 229, 96-105.

Matud MP (2004) Gender differences in stress and coping styles. Personality and Individual Differences 37, 1401-1415.

McHugh Power J, Hannigan C, Hyland P, Brennan S, Kee F and Lawlor BA (2020) Depressive symptoms predict increased social and emotional loneliness in older adults. Aging \& Mental Health 24, 110-118.

Meyler D, Stimpson JP and Peek MK (2007) Health concordance within couples: a systematic review. Social Science \& Medicine 64, 2297-2310.

Miller B and Cafasso L (1992) Gender differences in caregiving: fact or artifact? The Gerontologist 32, 498-507.

Miller RB, Mason TM, Canlas JM, Wang D, Nelson DA and Hart CH (2013) Marital satisfaction and depressive symptoms in China. Journal of Family Psychology 27, 677-682.

Moen P (2001) The gendered life course. In Binstock RH and George LK (eds), Handbook of Aging and the Social Sciences. San Diego, CA: Academic Press, pp. 179-196.

National Academies of Sciences, Engineering, and Medicine (2020) Social Isolation and Loneliness in Older Adults: Opportunities for the Health Care System. Washington, DC: The National Academies Press.

Pearlin LI, Schieman S, Fazio EM and Meersman SC (2005) Stress, health, and the life course: some conceptual perspectives. Journal of Health and Social Behavior 46, 205-219.

Pinquart M and Sörensen S (2006) Gender differences in caregiver stressors, social resources, and health: an updated meta-analysis. Journals of Gerontology: Psychological Sciences and Social Sciences 61B, P33-P45.

Russell DW (1996) UCLA Loneliness Scale (Version 3): reliability, validity, and factor structure. Journal of Personality Assessment 66, 20-40.

Sha S, Xu Y and Chen L (2020) Loneliness as a risk factor for frailty transition among older Chinese people. BMC Geriatrics 20, 300.

Siegel MJ, Bradley EH, Gallo WT and Kasl SV (2004) The effect of spousal mental and physical health on husbands' and wives' depressive symptoms, among older adults: longitudinal evidence from the Health and Retirement Survey. Journal of Aging and Health 16, 398-425.

Stokes JE (2017) Two-wave dyadic analysis of marital quality and loneliness in later life: results from the Irish Longitudinal Study on Ageing. Research on Aging 39, 635-656.

Strauss J and Thomas D (2007) Health over the life course. In Schultz TP and Strauss JA (eds), Handbook of Development Economics. Amsterdam: Elsevier, pp. 3375-3474.

Strawbridge WJ, Wallhagen MI and Shema SJ (2007) Impact of spouse vision impairment on partner health and well-being: a longitudinal analysis of couples. Journals of Gerontology: Psychological Sciences and Social Sciences 62B, S315-S322.

Valle G, Weeks JA, Taylor MG and Eberstein IW (2013) Mental and physical health consequences of spousal health shocks among older adults. Journal of Aging and Health 25, 1121-1142.

Victor CR, Rippon I, Quinn C, Nelis SM, Martyr A, Hart N, Lamont R and Clare L (2021) The prevalence and predictors of loneliness in caregivers of people with dementia: findings from the IDEAL programme. Aging \& Mental Health 25, 1232-1238. 
Warner DF and Adams SA (2016) Physical disability and increased loneliness among married older adults: the role of changing social relations. Society and Mental Health 6, 106-128.

Warner DF and Kelley-Moore J (2012) The social context of disablement among older adults: does marital quality matter for loneliness? Journal of Health and Social Behavior 53, 50-66.

Warner CB, Roberts AR, Jeanblanc AB and Adams KB (2017) Coping resources, loneliness, and depressive symptoms of older women with chronic illness. Journal of Applied Gerontology 38, 295-322.

Weeks JR (2020) Population: An Introduction to Concepts and Issues, 13th Edition. Boston, MA: Cengage Learning.

Wickrama KAS, O'Neal CW and Lorenz FO (2013) Marital functioning from middle to later years: a life course-stress process framework. Journal of Family Theory \& Review 5, 15-34.

Wong JS and Hsieh N (2019) Functional status, cognition, and social relationships in dyadic perspective. Journals of Gerontology: Psychological Sciences and Social Sciences 74B, 703-714.

Wong DFK, Ng TK and Zhuang XY (2019) Caregiving burden and psychological distress in Chinese spousal caregivers: gender difference in the moderating role of positive aspects of caregiving. Aging \& Mental Health 23, 976-983.

Xing T, Sun F, Wang K, Zhao J, Wu M and Wu J (2020) Vulnerability to fraud among Chinese older adults: do personality traits and loneliness matter? Journal of Elder Abuse \& Neglect 32, 46-59.

Yan Z, Yang X, Wang L, Zhao Y and Yu L (2014) Social change and birth cohort increase in loneliness among Chinese older adults: a cross-temporal meta-analysis, 1995-2011. International Psychogeriatrics 26, 1773-1781.

Yang F and Gu D (2020) Predictors of loneliness incidence in Chinese older adults from a life course perspective: a national longitudinal study. Aging \& Mental Health 24, 879-888.

Yang K and Victor C (2008) The prevalence of and risk factors for loneliness among older people in China. Ageing \& Society 28, 305-327.

Yorgason JB, Booth A and Johnson D (2008) Health, disability, and marital quality: is the association different for younger versus older cohorts? Research on Aging 30, 623-648.

You J, Fung H and Vitaliano P (2020) The pattern of social support seeking and its socio-demographic variations among older adults in China. European Journal of Ageing 17, 341-348.

Young R and Johnson DR (2015) Handling missing values in longitudinal panel data with multiple imputation. Journal of Marriage and Family 77, 277-294.

Yu B, Steptoe A, Niu K and Jia X (2020) Social isolation and loneliness as risk factors for grip strength decline among older women and men in China. Journal of the American Medical Directors Association 21, 1926-1930.

Zeng Y and Wang Z (2003) Dynamics of family and elderly living arrangements in China: new lessons learned from the 2000 Census. The China Review 3, 95-119.

Zhang QF (2004) Economic transition and new patterns of parent-adult child coresidence in urban China. Journal of Marriage and Family 66, 1231-1245.

Zhang J, Xu L, Li J, Sun L, Ding G, Qin W, Wang Q, Zhu J, Yu Z and Xie S (2018) Loneliness and health service utilization among the rural elderly in Shandong, China: a cross-sectional study. International Journal of Environmental Research and Public Health 15, 1468.

Zhao Y, Hu Y, Smith JP, Strauss J and Yang G (2014) Cohort profile: the China Health and Retirement Longitudinal Study (CHARLS). International Journal of Epidemiology 43, 61-68.

Zhong B-L, Chen S-L and Conwell Y (2016) Effects of transient versus chronic loneliness on cognitive function in older adults: findings from the Chinese Longitudinal Healthy Longevity Survey. American Journal of Geriatric Psychiatry 24, 389-398.

Zimmer Z, Hickey T and Searle MS (1997) The pattern of change in leisure activity behavior among older adults with arthritis. The Gerontologist 37, 384-392.

Zivin K and Christakis NA (2007) The emotional toll of spousal morbidity and mortality. American Journal of Geriatric Psychiatry 15, 772-779.

Cite this article: Luo Y (2021). Own health, spousal health and transitions in loneliness among middleaged and older adults in China. Ageing \& Society 1-27. https://doi.org/10.1017/S0144686X21001264 